\title{
Removal of basic dyes from solution using coconut shell charcoal
}

\author{
Siriwan Srisorrachatr ${ }^{1,2, a}$, Pariwat Kri-arb ${ }^{1}$, Sirawit Sukyang ${ }^{1}$ and Chutima Jumruen ${ }^{1}$ \\ ${ }^{1}$ Department of Chemical Engineering, Faculty of Engineering, Srinakharinwirot University, Bangkok 10110, Thailand \\ ${ }^{2}$ The Graduate School of Srinakharinwirot University, Bangkok 10110, Thailand
}

\begin{abstract}
This research aims to use agricultural waste as an adsorbent for dye removal from textile wastewater. Coconut shell charcoal (CSC), an agricultural waste, was used as dye adsorbent whilst basic yellow13 (BY13) and basic red14 (BR14) were used as representative dye used in textile manufactory. The removal of BY13 and BR14 from aqueous solution by CSC was investigated in batch adsorption at room temperature. Two parameters investigated in this research were $\mathrm{pH}$ of dyes solution; $\mathrm{pH} 2,7$, and 11, and particle size of adsorbents; 510$700 \mu \mathrm{m}$ and 1000-2000 $\mu \mathrm{m}$. The adsorption model, Langmuir and Freundlich were also examined. It was found that by CSC, BY13 and BR14 had maximum removal percentage of 23.6 and 55.7 at $\mathrm{pH}$ 11. Size of adsorbent had also shown the effect on dye removal, i.e.; increasing size with decreasing removal capability. The dye removal experimental data were fitted to Langmuir adsorption model for both dyes with maximum adsorption capacity $\left(\mathrm{q}_{\mathrm{m}}\right)$ for BY13 and BR14 of 19.76 and $22.93 \mathrm{mg} / \mathrm{g}$, respectively. It can be implied that the adsorption is monolayer. It can conclude that CSC can be used as adsorbent for basic dye removal from aqueous solution.
\end{abstract}

\section{Introduction}

Textile and handicraft dyeing use large volumes of water in wet processing operation and thereby, generates substantial quantities of wastewater containing large amount of dissolved dyestuff and other products such as dispersing agent, dye-bath carriers, salts, emulsifiers, leveling agent and heavy metals. It is nowadays well known that there is the need of treating dye wastewater by not only concerning primary and secondary treatment of organic matter and suspended solid removal but also a tertiary treatment mostly for residual colour removal. The removal of remaining dye from dye wastewater is currently of great importance in recent years. Dyestuffs have complex chemical structures, and are hard to degrade biologically. Basic dyes are used by several industries, such as textile, paper and colouring products. Although many conventional methods such as precipitation, ion exchange, solvent extraction, electrochemical treatment, biosorption, filtration and adsorption are used for dye removal from aqueous solution, these methods are either expensive or incomplete for removal of high concentration of contaminants and high energy consumption. Adsorption is a common one of the most powerful and extensively used realistic methods for dyestuff removal from wastewater and

\footnotetext{
${ }^{\text {a }}$ Corresponding author : siriwans@g.swu.ac.th
} 
discharges high water quality effluents without dyestuffs. Powdered activated carbon (PAC) has been the most widely used adsorbent for dyestuffs removal from wastewater. However, PAC is expensive and its use usually requires regeneration and reactivation procedure. Development and use of low cost adsorbents has been investigated by many researchers for effective removal of dyestuffs from wastewater. In Thailand, there are large amounts of coconut shell from coconut agro-industry waste. Although they can be used as organic fertilizer or solid fuel, for another benefit for using these materials, they can be used as the adsorbents in rural areas or small communities to conserve their environments. Exploring effective and low-cost adsorbent from agricultural waste may contribute to environmental sustainability and offer benefits for future commercial applications. The costs of activated carbon prepared from biomaterials are very low compared to the cost of commercial activated carbon. Many basic dyes, Basic Fuchsin dye [1], Basic Blue 3 [2] and Basic Red 9 [3] were studied with using agricultural wastes, in order to investigate the dye removal capacity. Another type of agricultural waste-adsorbent, coconut based adsorbent, are also interesting and many research papers were published. Coconut mesocarp was studied as an adsorbent for dye removal, such as Acid Blue158 (AB158) and Acid Yellow13 (AY13) [4] and textile dyes [5]. Low cost coconut shell based activated carbon (CSAC) was also examined for removal of Reactive Blue 19 (RB19) dye adsorption from aqueous solution [6]. Activated carbon from coconut shell was prepared via $\mathrm{H}_{2} \mathrm{SO}_{4}$ activation (CSAC) and its ability to remove textile dyes; maxilon blue GRL and direct yellow DY 12, from aqueous solutions were studied [7]. In this study, we attempt to investigate the removal ability of basic dyes from solution by coconut shell charcoal, which is agricultural waste in the community. The basic dyes used in this study are Basic Yellow 13 and Basic Red 14, which are those of dyestuff often used by the textile dyeing.

\section{Materials and methods}

\subsection{Materials and chemicals}

Basic Yellow 13 (BY13; $\mathrm{C}_{20} \mathrm{H}_{23} \mathrm{ClN}_{2} \mathrm{O}$ ) and Basic Red 14 (BR14; $\mathrm{C}_{23} \mathrm{H}_{26} \mathrm{ClN}_{3}$ ), shown in Figure 1, were obtained from President Chemical Co., Ltd and were used without any purification. NaOH (VWR International Limited), $\mathrm{HCl}$ (from Fluka Chemica) were used for adjusting dye solution $\mathrm{pH}$. All the chemicals used are analytical reagent grade and all the standards and reagent solutions were prepared with distilled water. Coconut shell charcoal (CSC) was purchased from BK Black Company, Bangkok, Thailand. The CSC with particle size of 510-700 $\mu \mathrm{m}$ was examined for Iodine number and Methylene Blue number. It was found that the values are $705.68 \mathrm{mg} / \mathrm{g}$ and $272.12 \mathrm{mg} / \mathrm{g}$ for Iodine Number and Methylene Blue Number, respectively.
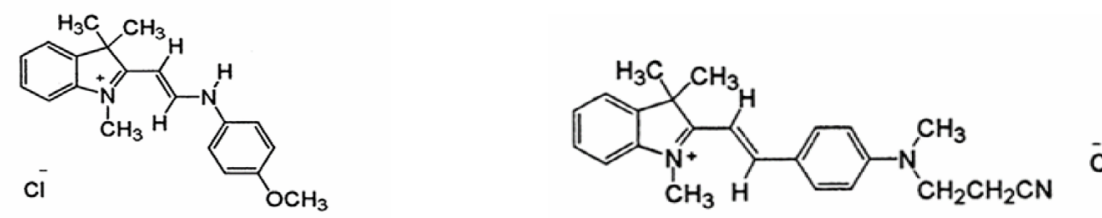

Figure 1. Chemical structure of (a) Basic Yellow 13 (BY13), [8] and (b) Basic Red 14 (BR 14), [9].

\subsection{Batch adsorption experiments}

All experiments in this study were examined as batch adsorption at room temperature. The parameters affecting on the removal capacity were investigated, such as $\mathrm{pH}$ of the solution and adsorbent size. A stock solution, $1000 \mathrm{mg} / \mathrm{L}$ Basic Yellow 13 (BY13) and Basic Red 14 (BR14), were prepared, and 
then diluted to $100 \mathrm{mg} / \mathrm{L}$ for initial concentration. The actual dye concentration was calculated from the calibation curve using spectrophotometrical method (SHIMADSU UV-visible spectrophotometer model UV-1610 (Japan) at 435 and 515 nanometers, respectively. The $\mathrm{pH}$ of the dye solution was adjusted to desired value by addition of dilute $\mathrm{HCl}$ or $\mathrm{NaOH}$ solutions. For batch study, 1.0 gram of coconut shell charcoal (CSC), particle size of 510-700 micrometer, was mixed with $200 \mathrm{~mL}$ of 100 $\mathrm{mg} / \mathrm{L}$ BY13 in elremenyer flask. The mixture was shaked on orbital shaker (Gallenkamp orbital shaker, England) with constant speed of $150 \mathrm{rpm}$ at room temperature. The dye solutions were then withdrawn at determined time interval periodically and seperated from the adsorbents by microsyringe filtration. The resulting dye solution was determined by SHIMADSU UV-visible spectrophotomer. The effect of solution $\mathrm{pH}$ on dye removal was also studied at $\mathrm{pH} \mathrm{2,7}$ and 11 . Then optimum $\mathrm{pH}$ was chosen for studying effect of CSC size on dye removal. The sizes of adsorbent used for study were $510-700 \mu \mathrm{m}$ and 1000-2000 $\mu \mathrm{m}$. The dye removal percentage and the amount of adsorbed dye $\left(\mathrm{q}_{\mathrm{e}}\right)$, were calculated by equation (1) and (2), respectively.

$$
\begin{aligned}
\% \text { Removal } & =\frac{C_{i}-C_{f}}{C_{i}} \times 100 \\
q_{e} & =\frac{C_{i}-C_{f}}{W} \times V
\end{aligned}
$$

where $\mathrm{C}_{\mathrm{i}}$ and $\mathrm{C}_{\mathrm{f}}$ are the initial and final concentrations $(\mathrm{mg} / \mathrm{L})$ of dye, W is the mass $(\mathrm{g})$ of adsorbent and $\mathrm{V}$ is the volume of dye solution $(\mathrm{L})$.

\subsection{Adsorption isotherm}

Adsorption isotherm experiment was carried out by mixing 1.0 gram CSC and $200 \mathrm{~mL}$ of dye solution of various concentration; 200, 250, 300, 400 and $500 \mathrm{mg} / \mathrm{L}$ at optimum $\mathrm{pH}$ and shaking at $150 \mathrm{rpm}$. Mixture of shaking dye and CSC was allowed to reach equilibrium about 2 hours, and then resulting solution was examined using UV-visible spectrophotometer for remaining dye concentration. For Langmuir adsorption model and Freundlich adsorption model, the calculated values of adsorbed dye $\left(\mathrm{q}_{\mathrm{e}}\right)$ and remaining dye concentration $\left(C_{e}\right)$ were plot according to equation (3) and (4), respectively.

Langmuir model:

$$
q_{e}=\frac{q_{m} K_{L} C_{e}}{\left(1+K_{L} C_{e}\right)}
$$

and can be linearized to be

$$
\frac{C_{e}}{q_{e}}=\frac{C_{e}}{q_{m}}+\frac{1}{K_{L} q_{m}}
$$

Freundlich model:

$$
q_{e}=K_{F} C_{e}^{\frac{1}{n}}
$$

which can be written in the linear form as

$$
\log q_{e}=\log K_{F}+\frac{1}{n} \log C_{e}
$$

where $C_{e}$ is equilibrium concentration $(\mathrm{mg} / \mathrm{L}), \mathrm{q}_{\mathrm{e}}$ is adsorption capacity $(\mathrm{mg} / \mathrm{g}), \mathrm{q}_{\mathrm{m}}$ is maximum adsorption capacity $(\mathrm{mg} / \mathrm{g}), \mathrm{K}_{\mathrm{L}}$ is Langmuir adsorption constant and $\mathrm{K}_{\mathrm{F}}$ is Freundlich adsorption constant. The plot of $C_{e} / \mathrm{q}_{\mathrm{e}}$ versus $C_{e}$ for Langmuir adsorption model will give the straight line with slope of $1 / \mathrm{q}_{\mathrm{m}}$ and intercept of $1 /\left(\mathrm{K}_{\mathrm{L}} \mathrm{q}_{\mathrm{m}}\right)$. For Freundlich adsorption model, plot of $\log \mathrm{q}_{\mathrm{e}}$ against $\log C_{e}$ also will be linear relationship. The relative coefficients of these models were calculated using linear least-squares fitting. 


\section{Results and discussion}

\subsection{Effect of pH on dye removal}

The effect of $\mathrm{pH}$ on the removal of BY13 and BR14 by CSC was studied at $\mathrm{pH} \mathrm{2,} 7$ and 11 wtih an initial dye concentration of $100 \mathrm{mg} / \mathrm{L}$. The BR14 removal percentages and removal capacity at the various $\mathrm{pH}$ were plotted in Figure 2. The values of percent removal of BR14 by CSC are 10.50, 29.40 and 55.70 at $\mathrm{pH} 2,7$ and 11, respectively. Whereas the removal percentages of BY13 are 29.40 at $\mathrm{pH}$ $2,45.87$ at $\mathrm{pH}$, and 56.28 at $\mathrm{pH} \mathrm{11}$, respectively. It can see that the maximum of both dye removals occur at $\mathrm{pH} 11$ and the removal percentage was decreased as $\mathrm{pH}$ lowered. The higher dye removal at higher $\mathrm{pH}$ may be due to the present negative charge of $\mathrm{OH}^{-}$ions on adsorbent surface interacting with the positive dye ions at the adsorption site. At acidic $\mathrm{pH}$, a significantly high electrostatic repulsion exists between the positively charged surface of the adsorbent and positively charged ionic dye.

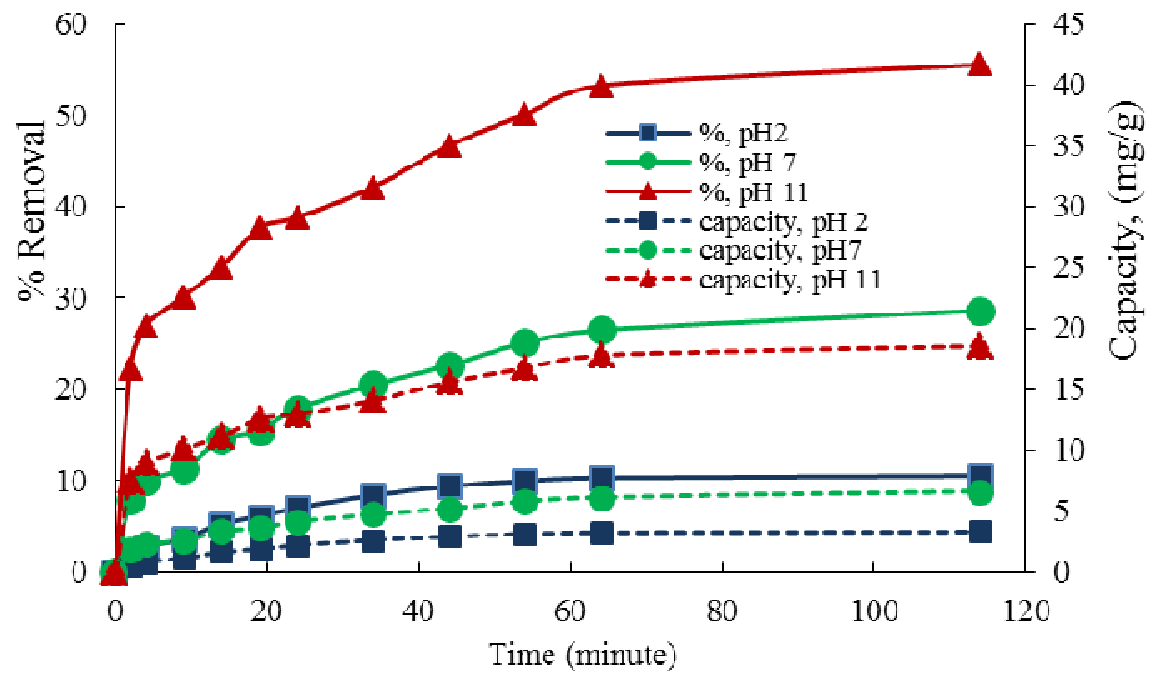

Figure 2. Effect of $\mathrm{pH}$ for BR14 removal by CSC of 500-710 $\mu \mathrm{m}$ at various times.

\subsection{Effect of adsorbent size on dye removal}

The size of adsorbent was varied in order to examine the effect of particle size on removal capacity. The experiment was carried out at $\mathrm{pH} 11$, the optimum $\mathrm{pH}$, with variation of 500-710 $\mu \mathrm{m}$ and 1000$2000 \mu \mathrm{m}$ CSC for BY14 and BR14 dye removal. From the experiment at $\mathrm{pH} 11$, it was found that the smaller size showed the higher removal capacity because of the larger specific surface of the smaller size. The experimental results were showed in Figure 3.

\subsection{Adsorption isotherm}

Adsorption isotherm describes the interaction between adsorbate and adsorbent materials. The experiment was carried out at $\mathrm{pH} 11$ with $200 \mathrm{~mL}$ solution of adsorbate concentration of 200, 250, 300,400 and $500 \mathrm{mg} / \mathrm{L}$ at $\mathrm{pH} 11$. The experimental data were fitted to Langmuir adsorption model (equation 3) and Freundlich adsorption model (equation 4) as shown in Figure 4 for BY13 and Figure 5 for BR14, respectively. 


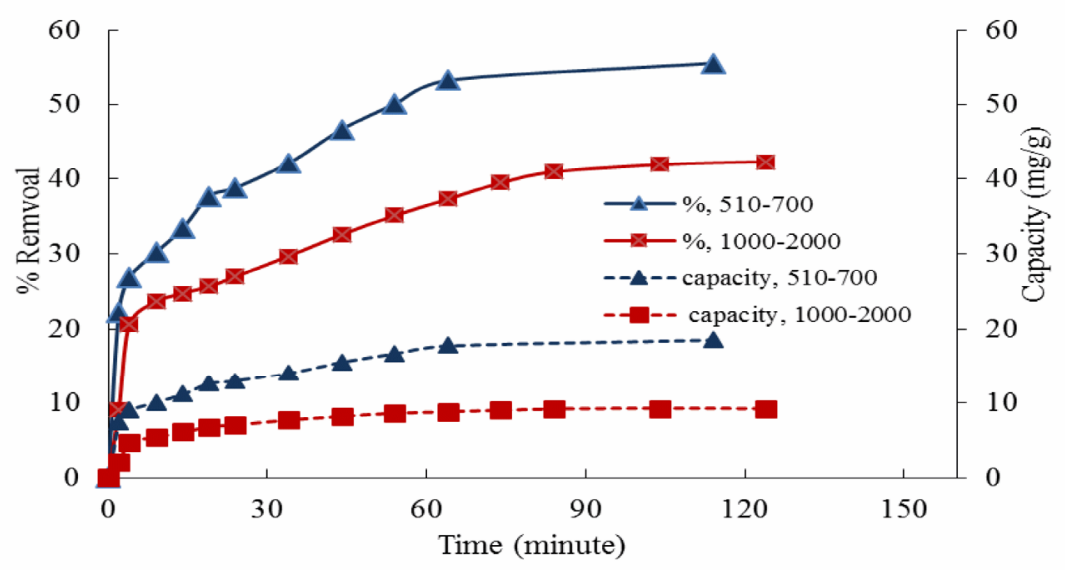

Figure 3. Effect of adsorbent sizes on BR14 removal by CSC, $\mathrm{pH} 11$ at various times.
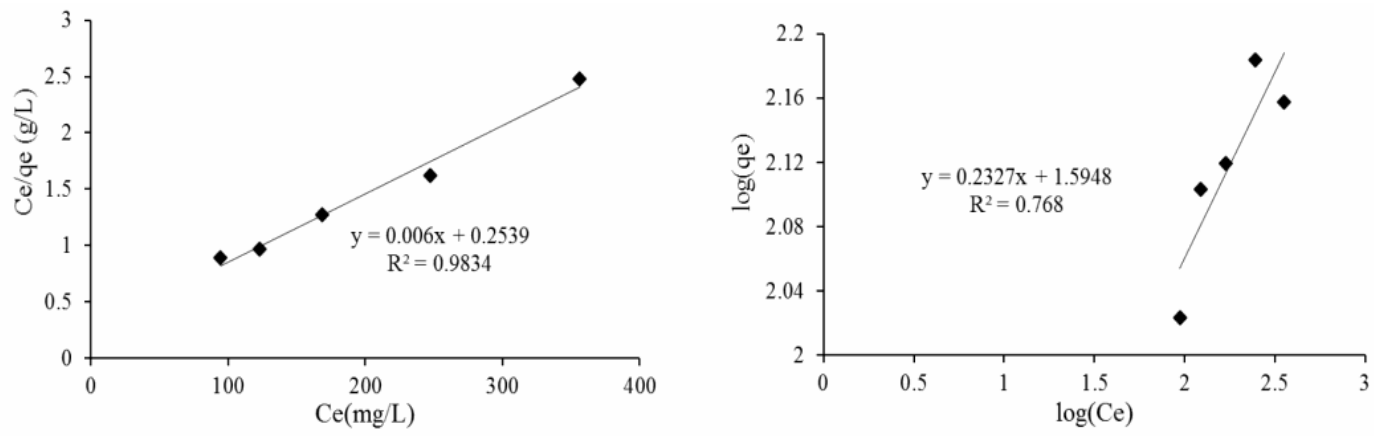

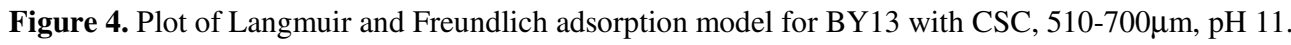
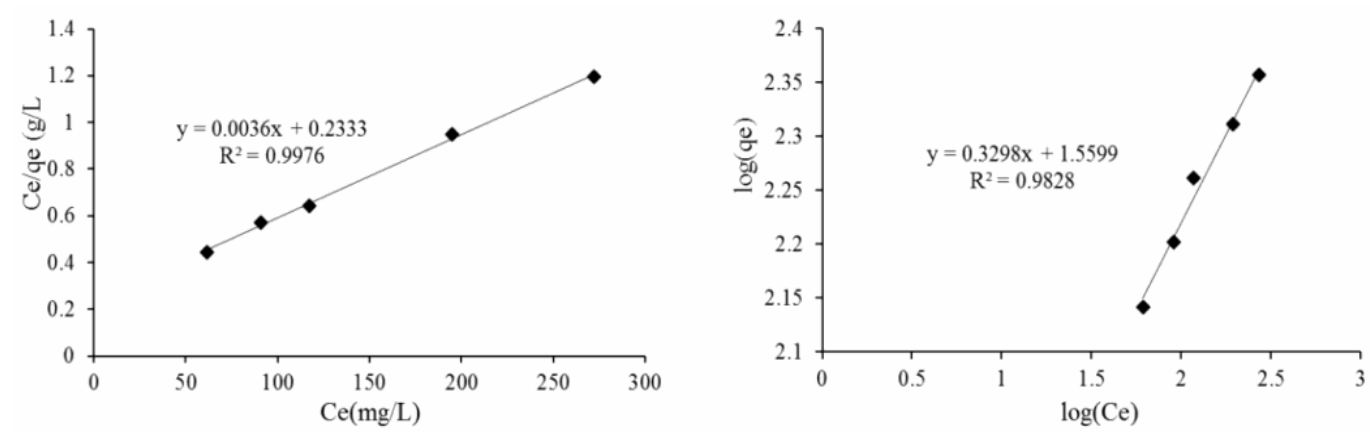

Figure 5. Plot of Langmuir and Freundlich adsorption model for BR14 with CSC, 510-700 $\mu \mathrm{m}, \mathrm{pH} 11$.

From the figures, it can see that the experimental data fitted to Langmuir adsorption model for both BR14and BY13. The caculated values for BR14 and BY13 in both model are presented in Table 1. Maximum adsorption capacity, $\mathrm{q}_{\mathrm{m}}$, were 22.93 and $19.76 \mathrm{mg} / \mathrm{g}$ and Langmuir adsorption constant, $\mathrm{K}_{\mathrm{L}}$, were $1.87 \times 10^{-2}$ and $1.99 \times 10^{-2} \mathrm{~L} / \mathrm{mg}$ for BR14 and BY13, respectively. It can be interpreted that the interaction between CSC and dye was ionic interaction with monolayer adsorption. Regarding to 
properties of CSC, Iodine Number and Methylene Blue Number, it could be pronounced that the CSC could be employed as a promising bio-adsorbent for basic dye removal from wastewater.

Table 1. Calculated values from adsorption model of BR14 and BY13 by coconut shell charcoal at pH 11 .

\begin{tabular}{|c|c|c|}
\hline $\begin{array}{c}\text { Calculated values from } \\
\text { Adsorption model }\end{array}$ & BR14 & BY13 \\
\hline Langmuir: & 0.004 & \\
Slope & 0.233 & 0.006 \\
Intercept & 22.93 & 0.253 \\
$\mathrm{q}_{\mathrm{m}}$ & 1.86 & 19.76 \\
$\mathrm{~K}_{\mathrm{L}} \times 10^{2}$ & 0.998 & 1.99 \\
$\mathrm{R}^{2}$ & & 0.983 \\
\hline Freundlich: & 0.329 & \\
Slope & 1.559 & 0.233 \\
Intercept & 3.08 & 1.595 \\
$\mathrm{n}$ & 36.29 & 4.29 \\
$\mathrm{~K}_{\mathrm{F}} \times 10^{2}$ & 0.983 & 39.33 \\
$\mathrm{R}^{2}$ & & 0.768 \\
\hline
\end{tabular}

\section{Conclusions}

The removal of Basic Yellow 13 and Basic Red 14 by CSC were investigated. The solution $\mathrm{pH}$ as well as adsorbent size can affect to the removal capacity. The removal at $\mathrm{pH} 11$ is the most comparing among that of $\mathrm{pH} 2,7$ and 11. Basic environment made the dye-CSC interaction more stronger than that of neutral or acidic solution. Larger size adsorbent shows lesser removal capapcity.The adsorption isotherm fitted to Langmuir model and maximum adsorption capacity, $\mathrm{q}_{\mathrm{m}}$, are found to be $19.76 \mathrm{mg} / \mathrm{g}$ and $22.93 \mathrm{mg} / \mathrm{g}$ and Langmuir adsorption constant, $\mathrm{K}_{\mathrm{L}}$, are $1.99 \times 10^{-2}$ and $1.86 .04 \times 10^{-2} \mathrm{~L} / \mathrm{mg}$ for Basic Yellow 13 and Basic Red 14, respectively. Thus these studies show that CSC, the disposed solid waste, can be effectively used as an alternative for commercial activated carbons for the removal of basic dye from aqueous solution.

\section{Acknowledgements}

Faculty of Engineering, Srinakharinwirot University is acknowledged for budget and equipment support. Assistant Professor Dr.Chanchira Jubsilp is also appreciated for managing the pictures.

\section{References}

1. M. E. Haddad, Journal of Taibah University for Science, 10, 664-667 (2016)

2. S.L. Chan, Y.P. Tan, A.H. Abdullah, and S.T. Ong, J. Taiwan Inst Chem E., 31, 306-315 (2016)

3. O. Duman, S. Tunç, and T.G. Polat, Micropor Mesopor Mat, 210, 176-184 (2015)

4. S. Srisorrrachatr, Annual Conference on Engineering and Technology, Proc. Con. (Nagoya, Japan, 2015)

5. S. Srisorrachatr, N. Pimpipat, and P. Senakham, Pure and Applied Chemistry International Conference, Proc. Con. PACCON, 663-666 (Chiang Mai, Thailand, 2012)

6. A.U. Isah, G. Abdulraheem, S. Bala, S. Muhammad, and M. Abdullahi, International Biodeterior. Biodegradation, 102, 265-273 (2015)

7. A.S. Aljeboree, A.N. Alshirifi, and A.F. Alkaim, Arabian J. Chem. (2014) DOI: 10.1016/j.arabjc. 2014.01.020

8. http://www.worlddyevariety.com/basic-dyes/basic-yellow-13.html

9. http://www.worlddyevariety.com/basic-dyes/basic-red-14.html 